\title{
Exploring lifelong learning outcomes among adult learners via goal orientation and information literacy self-efficacy
}

\author{
Ong Choon Hee, Lim Lee Ping, Adriana Mohd Rizal, Tan Owee Kowang, Goh Chin Fei \\ Azman Hashim International Business School, Universiti Teknologi Malaysia, Malaysia
}

\begin{tabular}{l}
\hline \hline Article Info \\
\hline Article history: \\
Received Aug 27, 2019 \\
Revised Oct 29, 2019 \\
Accepted Nov 22, 2019 \\
\hline
\end{tabular}

\section{Keywords:}

Adult learners

Goal orientation

Information literacy

Self-efficacy

Lifelong learning

\begin{abstract}
This study intends to explore the relationship between goal orientation, information literacy self-efficacy and lifelong learning outcomes of the adult learners. This study focuses on adult learners as they are actively participating in the development of the country socio-economy and recognized as the potential contributors towards the generation of knowledge-based economy. The findings of this study revealed that there was a significant relationship between mastery goal orientation and lifelong learning. However, information literacy self-efficacy was found to be a predictor instead of a moderator in the model. It is suggested that suitable and appropriate learning methods such as problem-based learning, case scenario presentations, portfolios and clinical debates can be designed specifically to facilitate adult learners' mastery goal learning motivation in promoting lifelong learning. In addition, training and retraining to equip adult learners with new information literacy skills so as to keep up their self-efficacy level will definitely enhance lifelong learning. This study provides a database on the impact of goal orientation and information literacy self-efficacy towards lifelong learning in implementing policy formation, educational structure redesign and human capital development. As such, suitable and appropriate learning methods such as problem-based learning, case scenario presentations, portfolios and clinical debates can be designed specifically to facilitate student learning motivation in the classroom.
\end{abstract}

Copyright (C) 2019 Institute of Advanced Engineering and Science. All rights reserved.

\footnotetext{
Corresponding Author:

Ong Choon Hee,

Azman Hashim International Business School,

Universiti Teknologi Malaysia,

Johor Bahru, 81310, Malaysia.

Email: ongchoonhee@gmail.com
}

\section{INTRODUCTION}

Lifelong learning is regarded as one of the most discussed topics in education today. The introduction of National Higher Education Strategic Plan beyond 2020 (NHESP) has highlighted the significance of lifelong learning in successfully reaching the goals of the country knowledge-based economy. NHESP intends is to spearhead programs that assist all sectors to grow outstanding human capital to overcome the forthcoming challenges. Due to the reason that adult learners in the country are participating vigorously to stimulate the country economy, they were recognized as the key players in building a strong foundation of the nation knowledge-based economy. If we would to move forward to a more knowledge intensive economy, a lifelong learning society needs to be produced. People should be given more opportunities to pursue lifelong learning education to obtain recognition for the level of achievement acquired. This specifically applies to adult learners as they are the drivers who make political, economic and social decisions in establishing knowledge based economy.

Researchers [1] stated that in the development of a highly educated nation, the country's priority was placed on educating the youth and undergraduates. Middle-aged and older-aged adults have little opportunity to pursue higher education or tertiary education. Although the Government has started to initiate professional 
programs for the working adults, it is still insufficient to generate lifelong learning outcomes among the adult learners as there are too few institutes meant for them like the universities of the Third Age, senior centres and learning-in-retirement institutes [1]. Most of the community colleges in Malaysia were filled by young learners. As far as lifelong learning in Malaysia is concerned, most of the participants of lifelong learning programs are in the younger age group. Adult learners may have been neglected and they received too little attention in the process of becoming more knowledgeable, skilful, competitive and innovative.

Though the Malaysia Education Blueprint (MEB) 2015-2025 has established an outcome of nation of lifelong learners among the 10-shifts, it is still obvious that the country has been concentrating and emphasizing on educating school children, youth and undergraduate learners all this long. According to researchers [2], it is obvious that the concept of lifelong learning is related to employability and productivity in Malaysia. Most of the adult learners would not declare themselves they have participated in lifelong learning activities if they did not take part in a formal education program. This is the perception that has been developed among the adult learners in the sense that informal learning activities to much lesser extent can be explained as the main lifelong learning activities. While the government has planned to ensure that lifelong learning is partly the national discourse and the main agent for promoting lifelong learning, it is essential to conduct a study on adult learners to investigate whether this group is progressing well with the lifelong learning plan and identify factors that are able to predict their lifelong learning outcomes.

According to [3], goal orientation is defined as multiple ways people may acquire in attaining goals and competence in accomplishment circumstances. Goal orientation is similar to encouragement and motivation which could impact their lifelong learning outcomes. Past literature has stated that information literacy self-efficacy is crucial in enhancing lifelong learning abilities [4, 5]. It is imperative for adult learners to have high information literacy self-efficacy level in order to cope with the rapid information growth and technology advancement [6]. Therefore, based on the above discussion, the researcher would like to fill the knowledge gap by addressing the below research questions:

RQ1: What is the relationship between goal orientations and life-long learning?

RQ2: Does information literacy self-efficacy moderate the relationship between goal orientations and lifelong learning?.

\section{LITERATURE REVIEW}

\subsection{Lifelong learning}

The notion of lifelong learning is about how individuals continuously improve their capabilities to face rapid social change [7]. It has been practiced by participants previously in various sectors such as education, social, political and industrial sector [8]. According to [9], lifelong learning is basically an advantage to the nation and its people. It assists personal development, social embracement and promotes economic competitiveness. Today, lifelong learning is not solely a personal concern, but an international agenda which is increasingly important. Though lifelong learning embraces formal and informal learning approach; but it is always being referred to recurrence education, adult continuing education, post-initial and popular education [10]. Therefore, lifelong learning is often perceived as lifelong education. Both lifelong learning and lifelong education share the same features and origins. They were referred to as learning process, structural and in methodological aspects [11]. It is about the continuity of education after formal schooling. However, lifelong learning will be more effective if it takes a proactive approach among individuals with appropriate goal orientation and information literacy self-efficacy which usually makes learning happens. In a nutshell, lifelong learning is a dominant discourse in the era of globalization and it is intensively connected to the formation of knowledge based economy in the country [12].

\subsection{Mastery goal orientation}

Mastery goal orientation is defined as intrinsically motivated individuals who attempt to enhance their knowledge, skills and abilities via becoming proficient in demanding situations. They treat hassles and difficulties as circumstances that make it possible to learn and believe that their competency and ability can be further improved with proficiency responses [13]. They demonstrate their achievement by evaluating the level of tasks and display lower task anxiety [14]. Adult learners with mastery goal orientation perceive mistakes as learning opportunities and persist in the establishment and growth of competence. They are able to assess their learning capabilities along their study and interested to understand the contents of their learning well. They spend their time in acquiring new knowledge and committed in academic studies and assignments. Typically, adult learners with mastery goal orientation intend to analyse the course content in details and seek for solution on the issues they encountered. They are motivated and desired to improve their abilities in learning new skills and acquiring new knowledge [15]. They persevere as a consequence of failure and use the setbacks they 
encounter to better their performance [16]. Mastery goal orientation is an essential goal orientation that promotes lifelong learning. Therefore, it is hypothesized that:

Hypothesis 1A: Mastery goal orientation has a positive relationship with lifelong learning.

\subsection{Performance-approach goal orientation}

Performance-approach goal orientation refers to individuals' intention to show their abilities and competence to gain favourable attention [15]. Those who display performance-approach goal orientation intend to outdo the others. They achieve performance-approach goals via their distinctive ability. However, they percieve their superiority is pre-determined and not able to change for better [13]. In the situation that they experience difficulties and obstacles, they incline to lessen their attempt and unwilling to involve in tasks where the possibility for errors to occur is high. They try to go after opportunities that attain positive evaluations and gain high performance with little effort [17]. Adult learners with performance-approach goal orientation make the best use of occasions that exhibit their competence and stay away from situations that display their incompetence [16]. They take part in the subjects they are familiar and show to others that they are better among the class participants. Generally, they intend to gain recognition in the class by comparing their performance with others. They like to be recognized as smart students. They are keen to learn and continue to make great efforts for better results. Therefore, it is hypothesized that:

Hypothesis 1B: Performance-approach goal orientation has a positive relationship with lifelong learning.

\subsection{Performance-avoidance goal orientation}

Adult learners with performance-avoidance goal orientation tend to stay away from occasions where they are unfavourable and incompetent compared with others. They have the tendency to stay away from exhibiting their incompetence and receiving negative evaluations [15]. They withdraw and decline to involve in works or duties that demonstrate their incompetence and inability. At times, they perceive demanding occasions as a situation that could inflict their weaknessnes and deficiencies [18]. These adult learners prefer to remove themselves from joining group activities such as presentation or assignment that they are not familiar about it. They attempt to avoid others from knowing that they are incapable of doing their assignments. At the same time, they incline to stay away from denying of a person's capability and keep themselves away from gaining unfavourable evaluation. In short, adult students who possess performance-avoidance goal orientation participate in acquiring knowledge only if they are not going to lose their name, status and reputation or revealing their inability in front of others. They are lacking of perseverance to pursue higher level of learning. Therefore, the following hypothesis is proposed:

Hypothesis 1C: Performance-avoidance goal orientation has a negative relationship with lifelong learning.

\subsection{Information literacy self-efficacy}

Information literacy is a skill for individuals to find, utilize and evaluate information [19]. Individuals with this skill have the ability to locate source and solution to any problem and use the information effectively [20]. Since information sources have become more complicated and complex, adult learners tend to be confronted with various types of information. Owing to the abundance of information, individuals must be able to use the skill of information literacy with strong belief and high confidence level. This is associated with information literacy self-efficacy where it can be explained as an individual's ability and belief in obtaining, evaluating and using information. Information literacy self-efficacy forms the basis of life-long learning and it is important to enhance the success of learners [21]. This applies to all forms of disciplines regardless of levels of education and learning environments. The higher the level of information literacy self-efficacy, the higher the learners can become self-directed and gain better control over their life-long learning outcomes [22].

\section{RESEARCH METHOD}

\subsection{Sample}

The population of this study consists of adult learners in a public university in Malaysia. It is estimated that there were 300 adult learners pursuing business and administration programs. The unit of analysis is individual learner and the targeted respondents are part-time adult students from various schools. The researcher will use a probability sampling method whereby random sampling technique was employed within the population. In this sampling process, respondents selected were adult learners who pursued their study on part-time basis. A total of 250 questionnaires were distributed to the adult learners in various levels of academic programs such as Bachelor's Degree, Masters and Doctorate programs. The researcher managed to collect 200 out of 300 questionnaires which yields a response rate of $66 \%$.

Int. J. Eval. \& Res. Educ. Vol. 8, No. 4, December 2019: 616 - 623 


\subsection{Measures}

Measures for the study variables were adapted from past studies. Lifelong learning measures were adapted from the Life-Long Learning Questionnaire (LLQ) (15 items) originally developed by researcher [23]. Measures for mastery goal orientation, performance-approach and performance-avoidance (13 items) were adopted from researcher [24]. The measures developed by researhcers [20] were employed to measure information literacy self-efficacy of the respondents. All responses were measured by using 5-point Likert scale. SmartPLS 3.0 was used to conduct data analysis in the present study.

\subsection{Participants}

The participants consist of $81(40.5 \%)$ males and 119 (59.5\%) females. The higher number of female adult learners indicates that females were more interested in pursuing continuing education than the males despite having multiple responsibilities in taking care of their family, career and handling household tasks. In the age categories, majority of the respondents were in the range of $26-45$ years old $(\mathrm{N}=119,55 \%)$. In terms of years of experience, most of adult learners have worked for 3-5 years $(\mathrm{N}=60,30 \%)$. Apart from that, most of the respondents were executives $(\mathrm{N}=75,37.5 \%)$. Master's program $(\mathrm{N}=85,42.5 \%)$ was found to be the most preferred academic program among the respondents.

\section{RESULTS AND DISCUSSION}

Partial Least Square - Structural Equation Modelling (PLS-SEM) was used to analyse the research model. SmartPLS software was employed to conduct the analytical procedures. As suggested by researchers [25], a two stage analytical procedure was used to assess the measurement and structural model of the study. Measurement model was assessed for composite reliability, indicator reliability, convergent validity and discriminant validity. Structural model was constructed to test the hypothesized relationship via bootstrapping procedure and blindfolding was used to assess predictive relevance of the model [25].

\subsection{Measurement model}

According to Table 1, it was found that all the indicators' outer loadings of the study variables were above 0.6 as recommended by researcher [26]. Next, indicator reliability was measured by Cronbach's Alpha and the results show that all values exceeded the recommended value of 0.70 [25].

Table 1. Results of the measurement model

\begin{tabular}{|c|c|c|c|c|}
\hline Constructs/Indicators & Loadings & Cronbach's Alpha & $\mathrm{CR}$ & AVE \\
\hline \multicolumn{5}{|l|}{ Lifelong Learning (LL) } \\
\hline LL13 & 0.6394 & 0.8752 & 0.9004 & 0.5026 \\
\hline LL14 & 0.6610 & & & \\
\hline LL2 & 0.8056 & & & \\
\hline LL3 & 0.6542 & & & \\
\hline LL4 & 0.7123 & & & \\
\hline LL6 & 0.6575 & & & \\
\hline LL7 & 0.7289 & & & \\
\hline LL8 & 0.7745 & & & \\
\hline LL9 & 0.7281 & & & \\
\hline \multicolumn{5}{|c|}{ Mastery Goal Orientation (MG) } \\
\hline MG1 & 0.8162 & 0.9158 & 0.9372 & 0.7494 \\
\hline MG2 & 0.901 & & & \\
\hline MG3 & 0.9134 & & & \\
\hline MG4 & 0.8401 & & & \\
\hline MG5 & 0.8536 & & & \\
\hline \multicolumn{5}{|l|}{ Performance Approach (PA) } \\
\hline PA4 & 0.9814 & 0.9389 & 0.9693 & 0.9404 \\
\hline PA5 & 0.9579 & & & \\
\hline \multicolumn{5}{|c|}{ Performance Avoidance (PV) } \\
\hline PV1 & 0.7815 & 0.7986 & 0.8791 & 0.7088 \\
\hline PV2 & 0.9143 & & & \\
\hline PV3 & 0.8246 & & & \\
\hline
\end{tabular}


Table 1. Results of the measurement model (Continued)

\begin{tabular}{|c|c|c|c|c|}
\hline Constructs/ Indicators & Loadings & Cronbach's Alpha & $\mathrm{CR}$ & AVE \\
\hline \multicolumn{5}{|c|}{ Information Literacy Self- Efficacy (IL) } \\
\hline \multicolumn{5}{|c|}{ IL1 } \\
\hline IL11 & 0.7296 & 0.8893 & 0.9104 & 0.5311 \\
\hline IL12 & 0.6781 & & & \\
\hline IL2 & 0.6721 & & & \\
\hline IL3 & 0.7747 & & & \\
\hline IL5 & 0.7493 & & & \\
\hline IL6 & 0.6821 & & & \\
\hline IL7 & 0.7599 & & & \\
\hline IL8 & 0.7541 & & & \\
\hline & 0.7504 & & & \\
\hline
\end{tabular}

Notes: CR - Composite Reliability, AVE- Average Variance Extracted

The composite reliability for the constructs was found to be above the threshold value of 0.70 [25] and achieved the minimum level of internal consistency. Further, to assess convergent validity of the measures, average variance extracted (AVE) with a threshold value of 0.50 was used as suggested by researchers [27]. Table 1 shows that all AVE values of the constructs were exceeding the minimum value of 0.50 . On the other hand, discriminant validity was measured to ensure the constructs are different from one another [25]. The Fornell-Larcker criterion was employed to compare the square root of AVE for each construct as shown inTable 2. The square root of the AVEs (in bold) were greater than other values in the column and row, indicating that discriminant validity of the constructs has been established [25].

Table 2. Discriminant validity

\begin{tabular}{|c|c|c|c|c|c|}
\hline & $\begin{array}{l}\text { Information Literacy } \\
\text { Self-Efficacy (IL) }\end{array}$ & $\begin{array}{l}\text { Lifelong Learning } \\
\text { (LL) }\end{array}$ & $\begin{array}{c}\text { Mastery Goal } \\
\text { (MG) }\end{array}$ & $\begin{array}{c}\text { Performance } \\
\text { Approach } \\
\text { (PA) }\end{array}$ & $\begin{array}{c}\text { Performance } \\
\text { Avoidance } \\
\text { (PV) }\end{array}$ \\
\hline $\begin{array}{c}\text { Information Literacy Self- } \\
\text { Efficacy (IL) }\end{array}$ & 0.7288 & & & & \\
\hline Lifelong Learning (LL) & 0.6159 & 0.7089 & & & \\
\hline Mastery Goal (MG) & 0.5401 & 0.6237 & 0.8657 & & \\
\hline Performance Approach (PA) & 0.2002 & 0.1739 & 0.0998 & 0.9697 & \\
\hline
\end{tabular}

\subsection{Structural model}

The structural model in Table 3 indicates path relationships among the study variables as hypothesized in the literature review. Path coefficients $(\beta)$ and coefficient of determination (R2) were used to evaluate the adequacy of the structural model [26]. Bootstrapping procedures were employed to generate path coefficients and its corresponding t-values [27]. Referring to the outputs of the structural model (Table 3), mastery goal orientation (MG) was discovered to be significantly associated with lifelong learning (LL) $(\beta=0.3731, t=$ 3.6326). Therefore, H1A was supported. However, performance approach and performance avoidance were found not significantly related to lifelong learning as their empirical t-values were below 1.96 of the critical tvalue. This signifies that $\mathrm{H} 1 \mathrm{~B}$ and $\mathrm{H} 1 \mathrm{C}$ were not supported. To test the moderating effects of information literacy self-efficacy (IL) on the relationships between MG, PA, PV and LL, items of IL and items of the respective MG, PA and PV were multiplied to create interaction constructs to predict LL [28]. The results in Table 3 show that path coefficients for all the interaction constructs were not significant (i.e. $t$-values were below 1.96) thus indicating information literacy self-efficacy was not able to moderate the relationships between the tested variables. Therefore, H2A, H2B and H2C were not supported. Nevertheless, it was discovered that information literacy self-efficacy (IL) has a significant relationship with lifelong learning (LL) $(\beta=0.3195, t=3.0341)$ as shown in Figure 1. It implies that although information literacy self-efficacy fail to moderate the relationships but it has predictive ability towards lifelong learning. The value of coefficient of determination (R2) of the endogenous latent variable is 0.477 , thus indicating the model is moderately fit (R2 $>0.35)$ as suggested by researcher [26]. The model's predictive ability was evaluated with Stone-Geisser's value $(\mathrm{Q} 2)$ and it is greater than zero $(\mathrm{Q} 2=0.2558)$. Hence, the structural model's predictive relevance was established [29]. 
Table 3. Results of the structural model

\begin{tabular}{cccccc}
\hline Hypothesis & Path & Std Beta & Std Error & T-value & Decision \\
\hline H1A & MG $\rightarrow$ LL & $0.3731^{* *}$ & 0.1027 & 3.6326 & Supported \\
H1B & PA $\rightarrow$ LL & -0.1248 & 0.1013 & 1.2312 & Not Supported \\
H1C & PV $\rightarrow$ LL & 0.1369 & 0.1122 & 1.22 & Not Supported \\
H2A & IL * MG $\rightarrow$ LL & -0.1092 & 0.1536 & 0.7111 & Not Supported \\
H2B & IL * PA $\rightarrow$ LL & 0.0316 & 0.1175 & 0.2686 & Not Supported \\
H2C & IL * PV $\rightarrow$ LL & -0.1956 & 0.2061 & 0.9488 & Not Supported \\
**Significant at the 0.01 level & & & &
\end{tabular}

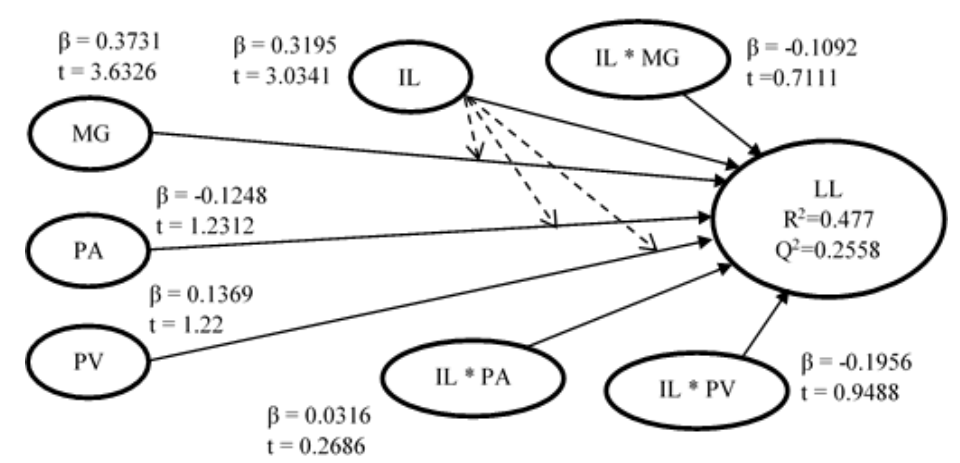

Figure 1. The structural model

According to the data analysis results, adult learners were found to possess mastery goal orientation which is positively associated with lifelong learning (H1A). It is perceived that the adult learners are moving towards personal growth with achievement related behaviour [30]. They display adaptive characteristics such as self-efficacy and preference for challenge [31]. In terms of academic achievement, they have the tendency to maintain persistence in academic performance and able to overcome difficulties and distracting events in their study [32]. These characteristics will eventually lead to positive lifelong learning outcomes such as enculturation of a first class human capital in creating knowledge-based economy. In relation to the above findings, it is suggested that higher education institutions should offer flexible learning, case scenario presentations, portfolios, clinical debates and problem-based learning in facilitating mastery goal oriented students to promote lifelong learning [33]. The learning methods are akin to action learning that generates interest and dynamic interactions in stimulating positive lifelong learning outcomes [34]. On the other hand, performance-approach and performance avoidance goal orientation were found not significantly associated with lifelong learning (H1B \& H1C). The plausible reasons to explain these findings are that adult learners may not have the tendency to outperform others during their study. They prefer to develop their skills and competence through mastering challenging situations and view errors as part of their learning process [24]. They do not prefer to achieve learning outcomes through little effort [17]. Further inspection of the moderating role of information literacy self-efficacy $(\mathrm{H} 2 \mathrm{~A}, \mathrm{H} 2 \mathrm{~B} \& \mathrm{H} 2 \mathrm{C})$ revealed that it was not a moderator but instead a strong predictor. This finding is consistent with the study of researcher [19], indicating that information literacy self-efficacy is able to predict lifelong learning by forming the basis of finding, utilizing and evaluating information. It is able to strengthen adult learners' ability to gain positive experiences in accessing and using information efficiently [35]. Therefore, it is suggested that training and re-training to equip the adult learners with new information literacy skills so as to keep up their self-efficacy will definitely produce positive lifelong learning outcomes in the existing setting.

\section{CONCLUSION}

This research attempts to make potential applications in providing avenues to promote lifelong learning via goal orientation and information literacy self-efficacy. As such, suitable and appropriate learning methods can be designed to facilitate adult learners' learning motivation in the classroom. In addition, this research supports higher education institutions to raise the quality of existing lifelong learning approach in a way that it is more realistic, innovative and interactive. As such, adult learners will become more independent, creative and dynamic in the near future. If higher education institutions emphasize on the appropriate teaching and mastery goal learning orientation, it will definitely enhance adult learners' learning ability in achieving the 3rd shift of the Malaysia Education Blueprint 2015-2025 and once again, it will put the country in its right path to transform into a knowledge-based economy. 


\section{ACKNOWLEDGEMENTS}

The authors would like to express their gratitude to Universiti Teknologi Malaysia GUP Vot (15J99) and the Ministry of Higher Education Malaysia for providing financial support to publish this paper.

\section{REFERENCES}

[1] Merriam, S.B. and Mohamad, M., "How cultural values shape learning in older adulthood: A case of Malaysia," Adult Education Quarterly, vol. 51(1), pp. 45-58, 2000.

[2] Bax, M. R. N. and Hassan, M. N. A., "Lifelong learning in Malaysia," 2003. [Online]. Available: http://www.unesco.org/iiep/eng/research/highered/lifelm/malaysia.pdf

[3] Dowson, D. and McInerney, M., "Psychological parameters of students' social and work avoidance goals: A qualitative investigation," Journal of Educational Psychology, vol. 93(1), pp. 35-42, 2001.

[4] Coolahan, J., "Teacher education and the teaching career in an era of lifelong learning," OECD Education Working Papers, No. 2, OECD Publishing, 2002. [Online]. Available: http://dx.doi.org/10.1787/226408628504

[5] Chang, D. F., Wu, M. L., and Lin, S. P., "Adults engaged in lifelong learning in Taiwan: Analysis by gender and socio-economic status," Australian Journal of Adult Learning, vol. 52(2), pp. 310-335, 2012.

[6] Diehm, R., and Lupton, M., "Learning information literacy," Information Research, vol. 19(1), 2014. [Online]. Available: http:// eprints.qut.edu.au/68639/1/68639.pdf

[7] United Nations Educational, Scientific and Cultural Organisation (UNESCO), Open and Distance Learning: Trends, Policy and Strategy considerations. France: Division of Higher Education, 2002.

[8] Taylor, R., "Lifelong learning and the new educational order," Studies in the education of Adults, vol. 34(2), pp. 189-191, 2002.

[9] Reeve, F., Cartwright, M., and Edwards, R., "Organizing learning," In Supporting Lifelong Learning, vol. 2, Organising Learning London: Routledge, 2004.

[10] Hodgson, A., "An international and historical context for recent policy approaches to lifelong learning in the UK," In Hodgson, A. (ed). Policies, Politics and the Future of Lifelong Learning from 14+. London: Kogan Page, 2000.

[11] Ng, J. G. H. and Young, E. C. M., "Servicing the service industries; lifelong education as human capital investments for hong kong," Research report: Serial No. 002, 2000. [Online]. Available: http://hkuspace.hku.hk/about/aboutphp?action=research

[12] Long, C.S., Kowang, T.O., Chin, T.A., and Hee, O.C., "Improving organizational performance through training unction: A review," International Business Management, vol. 10(4), pp. 475-478, 2016.

[13] Dweck, C.S., Hong, Y., and Chiu, C., "Implicit theories: Individual differences in the likelihood and meaning of dispositional influence," Personality and Social Psychology Bulletin, vol. 19(5), pp. 644-656, 1993.

[14] Sujan, H., "Learning orientation, working smart and effective selling," Journal of Marketing, vol. 58(3), pp. 39-52, 1994

[15] VandeWalle, D., "Development and validation of a work domain goal orientation instrument," Educational and Psychological Measurement, vol. 57(6), pp. 995-1015, 1997.

[16] Elliot, A. J., "Approach and avoidance motivation goals," Educational Psychologist, vol. 34(3), pp. 169-189, 1999.

[17] DeShon, R.P., and Gillespie, J.Z., "A motivated action theory account of goal orientation," Journal of Applied Psychology, vol. 90(6), pp. 1096-1127, 2005

[18] Elliot, A. J., "A conceptual history of the achievement goal construct," In Elliot, A.J., \& Dweck, C.S. (Eds), Handbook of Competence and Motivation (pp. 52-72). New York, NY: Guilford Press, 2005.

[19] Sheehy, E. J., Student Teacher Mentoring Program: Teacher Training for Information Literacy in the Classroom. $\mathrm{PhD}$ Thesis, Unpublished. New York, USA: University of Albany, State University of New York, 2001

[20] Kurbanoglu, S., Akkoyunlu, B., and Umay, A., "Developing the information literacy self-efficacy scale," Journal of Documentation, vol. 62(6), pp. 730-743, 2006.

[21] Sacchanand, C., "Information literacy instruction to distance students in higher education: Librarians' key role," 68th IFLA Council and General Conference, 18-24 August, 2002.

[22] ALA (American Library Association), "Information literacy competency standards for higher education," 2000. [Online]. Available: http://www.ala.org/ala/mgrps/divs/acrl/standards/standards.pdf

[23] Cournoyer, B.R., The social work skills workbook. Brooks/Cole, Cengage Learning: Belmont, CA, 2014.

[24] Ong, C.H., "Goal orientation of adult students towards learning strategies: The Malaysian context," Psychological Thought, vol. 7(2), pp. 156-167, 2014.

[25] Hair Jr, J. F., Hult, G. T. M., Ringle, C., and Sarstedt, M., A primer on partial least squares structural equation modelling (PLS-SEM): Sage Publications, 2016.

[26] Chin, W. W., "How to write up and report PLS analyses," In: Esposito Vinzi V, Chin W. W., Henseler J. Wang H (eds.), Handbook of partial least squares: concepts, methods and applications, pp. 655-690, Springer, Heidelberg, 2010. Chin, W. W., "Commentary: Issues and opinion on structural equation modelling," MIS Quarterly, vol. 22(1), pp. 7-16, 1998.

[27] Henseler, J., Christain, M., Ringle, R., and Sinkovics, "The use of partial least square path modelling in international marketing," Advances in International Marketing, vol. 20, pp. 277-319, 2009.

[28] Henseler, J., and Fassott, G., "Testing moderating effects in PLS path models: An illustration of variables procedures," In V. Esposite Vinzi, W.W. Chin, J. Henseler, and H. Wang (Eds.), Handbook of partial least squares. Heidelberg: Springer, 2010 
[29] Fornell, C., and Cha, J., "Partial least squares," In R.P. Bagozzi (Ed.) Advanced Methods of Marketing Research (pp. 52-78). Cambridge, MA: Blackwell, 1994.

[30] Ames, C., and Archer, J., "Achievement goals in the classroom: Students' learning strategies and motivation processes," Journal of Educational Psychology, vol. 80(3), pp. 260-267, 1988.

[31] Midgley, C., Goals, goal structures and patterns of adaptive learning. Mahwah, NJ: Erlbaum, 2002.

[32] Zimmerman, B. J., and Martinez-Pons, M., "Student differences in self-regulated learning: Relating grade, sex, and giftedness to self-efficacy and strategy use," Journal of Educational Psychology, vol. 82(1), pp. 51-59, 1990.

[33] Wade, W., "Introduction," In W. Wade, K. Hodgkinson, A. Smith, \& J. Arfield (Eds.), Flexible learning in higher education (pp. 12-16). London, United Kingdom: Kogan, 1994.

[34] Kwan, C.Y., "What is problem-based learning? It is magic, myth and mind-set," Centre for Development of Teaching and Learning, NUS, vol. 3(3), pp. 1-2, 2000.

[35] Kay, R., and Ahmadpour, K., "Information literacy-Developing a framework for educators: A review of literature," EdMedia: World Conference on Educational Media and Technology, vol. 2015(1), pp. 1079-1084, 2015. 